\title{
Behaviour of solar wireless sensor network in saharan region under different scenarios consideration
}

\author{
Boubakeur Hamlili $^{1}$, Khelifa Benahmed ${ }^{2}$, Brahim Gasbaoui ${ }^{3}$ \\ ${ }^{1,3}$ Department of Electrical Engineering, Tahri Mohamed Bechar University, Algeria \\ ${ }^{2}$ Department of Mathematics and Computer Science, Tahri Mohamed Bechar University, Algeria
}

\section{Article Info \\ Article history: \\ Received Oct 29, 2019 \\ Revised Nov 25, 2019 \\ Accepted Dec 10, 2019}

\section{Keywords:}

Boost

IC algorithm

MPPT

PV

Sensor networks

\begin{abstract}
This paper deals with the Wireless Sensor Network comportment in the south west region precisely Bechar city. Algeria has the highest technical and economic potentials for solar power exploitation in the Middle East and North Africa region. In this paper, the focus is on the behaviour of Wireless Sensor Network (WSNs) supplied by solar panel PV connected to node via boost converter (DC/DC) controlled by maximum power point tracking (MPPT) technique, using the incremental conductance (IC) algorithm to extract maximum power. In Our present work, many tests were carried out. The WSNs are examined under sever and different temperature and irradiation variation. The obtained result is satisfactory for our (WSNs) simulated in a MATLAB/SIMULINK environment. The performances of the proposed strategy controller give a satisfactory simulation results.
\end{abstract}

Copyright $(0) 2020$ Institute of Advanced Engineering and Science. All rights reserved.

\section{Corresponding Author:}

Boubakeur Hamlili,

Department of Electrical Engineering,

Tahri Mohamed Bechar University.

P.o.box 417 Bechar - 08000 Algeria.

Fax (+213) 049239024.

Email: boubakeur.adel@yahoo.fr

\section{INTRODUCTION}

The miniaturization of embedded electronic equipment continues to increase while they are destined to accomplish more and more complex tasks. Due to their small size and the high energy consumption imposed on them, the Constituents of sensor networks can not compete with computers, smart phones, tablets or other handheld terminals in terms of processing capacity of data, storage and communication. It is therefore important to be able to consider energy consumption very early in the cycle of design and development of embedded systems $[1,2]$.

This study focuses on a particular case of these types of miniaturized equipment these are the wireless sensor nodes. These are electronic devices communicating with each other with wireless links, and whose primary functions areto collect and transmit data in a completely autonomous way in energy. These communicating systems thus constitute the network and are called nodes sensors. They are necessarily each equipped with a catchment unit to observe the environment in which they are placed. The association of these nodes forms the wireless sensor network (WSN). Sensor nodes can be immobile or mobile. Their position in the network is not necessarily predetermined because they can be randomly dispersed in a geographical area (with an algorithm and a self-organizing protocol) or their positions can be specified and organized in a targeted area (pre-configured topology) [1,3]. A sensor network is connected by a point to a host system. This connection point is called the well. All data collected by each node are routed to the well or collection point via a multi-hop architecture or only a jump according to the topology of the network $[1,4]$. 
The interest in this article is exactly the Wireless Sensor Networks behaviour supplied by solar panel PV connected to node under Different Scenarios (Temperature and Irradiation), via boost converter controlled by MPPT technique, using the IC algorithm to extract maximum power. It is therefore necessary to replace or associate another source of energy then the only source of energy provided by the battery by proposing another comparative technique in order to contribute to the improvement of the performances and the conservation of the energy in the sensor to extend the life of (WSN). The objective of this study consists of the boost converter use controlled by MPPT technique, using the IC algorithm during three scenarios service of the node. Simulation and results are simulated in MATLAB/SIMULINK environment. The proposed studies give satisfactory results for our (WSN) and which will be more interesting for the control and the follow-up of the inverting in the Sahara regions and especially for the types of Multimedia data or for mobile nodes. To achieve this goal, the plan will be the rest of this document in seven sections such as: generalities of nodes in wireless sensor networks, then photovoltaic panel (PV) modeling, and later on the principle of the IC algorithm, section 5 Boost DC-DC converter for wireless sensor array, simulation results and discussion in section 6 , at the end a conclusion is given.

\section{BASIC CONCEPTS of a WSN and DISSIPATION of ENERGY in SENSOR NODE}

The Wireless Sensor Network (WSN) provides the means of monitoring, temperature, sound, pressure, among others. They are often deployed autonomously and distributed through the network to a centralized location $[2,5]$. WSN is a set of small devices that have very limited resources. Typically, they are powered by batteries and they are distributed in an inaccessible environment, it seems impossible to perform a battery replacement if the batteries are exhausted. Not to mention the massive transmission and processing of the WSN network, which makes it more vulnerable to energy depletion $[3,6]$.

The life of a WSN strongly depends on the lifetime of each node in the network. For this reason, it is very important to consider that the energy consumption in the nodes wireless sensors. In order to properly consider this consumption, the different activities of the nodes must be take into account in the network. Thus, the general characteristics of the hardware and software in the sensor nodes and the overconsumption often encountered in the WSN we will be talked later. A sensor node is autonomous in energy, it has its own source of energy (battery) [1]. It is equipped with an acquisition device (sensor), a processing, a communication unit and possibly a displacement system. The processing unit is often attached to a flash memory to be able to store data and process them with minimal energy consumption [7], so as to interconnect with other nodes, it has a transceiver module often called a communication unit with a very high energy consumption. To ensure the long life of the WSN, another source of energy is used and this is mentioned in the next section.

\section{ANALYSIS and MODELLING of the PHOTOVOLTAIC (PV) SYSTEM for SENSOR NODE}

A stand-alone PV system typically consists of three principle blocks: PV array, the MPPT control element and DC-DC boost converter. Examination will be show about them in the following paragraph. Basically, the PV cell can be described as a semiconductor device, which produce electricity when exposed to light. A typical solar cell produces 0.5 to 0.8 volts. To have high voltage, the PV cells has to be connected to series and for high current the cells must be in parallel. In this paper, the solar module is developed with the help of mathematical model that follows. Here, the single diode model has been proposed. To have better accuracy, in single diode model the series as well as shunt resistance ar also considered [8]. The equivalent cell current equation is given as.

Where the output current and output voltage of PV cell are presented by $I_{p v}$ and $V_{p v}$ correspondingly, $I_{p H}$ is the photocurrent, the reverse saturation current of diode is designed by $I_{0}$, the diode voltage and the diode current are presented by $V_{D}, I_{D}$ respectively, the symbol of diode idealist factor and the Boltzmann constant are a and $\mathrm{K}$, and the sign of the $\mathrm{p}-\mathrm{n}$ junction temperature and the electron charge are $\mathrm{T}$ and $\mathrm{q} . \mathrm{Ki}$ and $\mathrm{Kv}$ gives the designation of short-circuit current/temperature coefficient and open-circuit voltage/temperature coefficient respectively and $G_{s t c}$ presented the actual sun irradiation and nominal sun irradiation $10^{3} \mathrm{~W} / \mathrm{m}^{2}$ one to one, difference between actual temperature and nominal one $\left(25^{\circ} \mathrm{C}\right)$ is the $\Delta T$, the nominal photocurrent $\left(25^{\circ} \mathrm{C}\right.$ and $\left.10^{3} \mathrm{~W} / I_{p v} m^{2}\right)$ is present by $I_{p h s t c}, N_{p}$ And $N_{s}$ the number of elements joined in parallels and series respectively, open circuit voltage is represented by $V_{o c}$, short circuit voltage is designed by $I_{s c}$, finally MPP is the maximum power point. The single diode model which includes the series resistance $R_{S}$ and shunt the resistance $R_{S}$, where the output current can be written as 


$$
I_{p V}=I_{p h}+I_{0}\left(e^{\frac{\left(V_{p v}+R_{s} T_{p v}\right)}{a V_{T}}}-1\right)-\frac{V+I_{p v} R_{s}}{R_{p}}
$$

with

$$
\mathrm{V}_{\mathrm{T}}=\frac{\mathrm{N}_{\mathrm{s}} \mathrm{KT}}{\mathrm{q}}
$$

The photocurrent is given by

$$
\mathrm{I}_{\mathrm{ph}}=\left(\mathrm{I}_{\mathrm{ph}, \mathrm{STC}}+\mathrm{K}_{1} \Delta \mathrm{T}\right) \frac{\mathrm{G}}{\mathrm{G}_{\mathrm{STC}}}
$$

and the reverse saturation current is

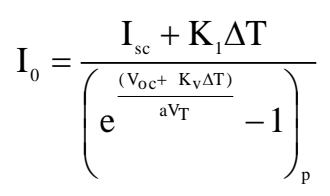

The change in temperature and irradiance, directly affects the short circuit current $I_{s c}$, But the diode reverse saturation current is mainly affected by temperature only. The power obtained from PV module depends on temperature and irradiance [8].

\section{MAXIMUM POWER POINT TRACKING and PRINCIPE of IC ALGORITHMS}

IC was planned to abas on a remark of P-V characteristic curve. This algorithm was created in 1993 and was anticipated to overwhelmed some drawback of $\mathrm{P} \& \mathrm{O}$ algorithm. IC increases the tracking time and to produce additional energy on a massive irradiation changes environment [9]. The MPP can be designed by using the relation between $\frac{d I}{d V}$ and $\frac{-I}{V}$.

If $\frac{d I}{d V}$ is negative then MPPT lies on the right side of recent position and if the MPP is positive the MPPT is on left side [6]. The equation of IC method is:

$$
\frac{d P}{d V}=\frac{d(V \cdot I)}{d V}=I \frac{d V}{d V}+V \frac{d I}{d V}=I+V \frac{d I}{d V}
$$

Mpp is reached when

$$
\begin{aligned}
& \frac{\mathrm{dI}}{\mathrm{dV}}=-\frac{\mathrm{I}}{\mathrm{V}} \\
& \frac{\mathrm{dP}}{\mathrm{dV}} \succ 0 \text { then } \mathrm{V}_{\mathrm{p}} \prec \mathrm{V}_{\text {mpp }} \\
& \frac{\mathrm{dP}}{\mathrm{dV}}=0 \text { then } \mathrm{V}_{\mathrm{p}}=\mathrm{V}_{\text {mpp }} \\
& \frac{\mathrm{dP}}{\mathrm{dV}} \prec 0 \text { then } \mathrm{V}_{\mathrm{p}} \succ \mathrm{V}_{\text {mpp }}
\end{aligned}
$$

If MPP deceits on right side, $\frac{d I}{d V}<-\frac{I}{V}$ and then the PV voltage must be diminished to touch the MPP $[10,11]$. IC methods can be practiced for finding the MPP, progress the PV competence, reduce power loss and system cost $[12,13]$. Application IC on a microcontroller created more stable performance when it compared to P\&O [14, 15-17]. The fluctuation around MPP area also can be blocked in trade of its implementation difficulty. Tracking time still not fast since the voltage increase and decrement had been nominated manually by trial and error, IC algorithm can be seen on Figure 1. 


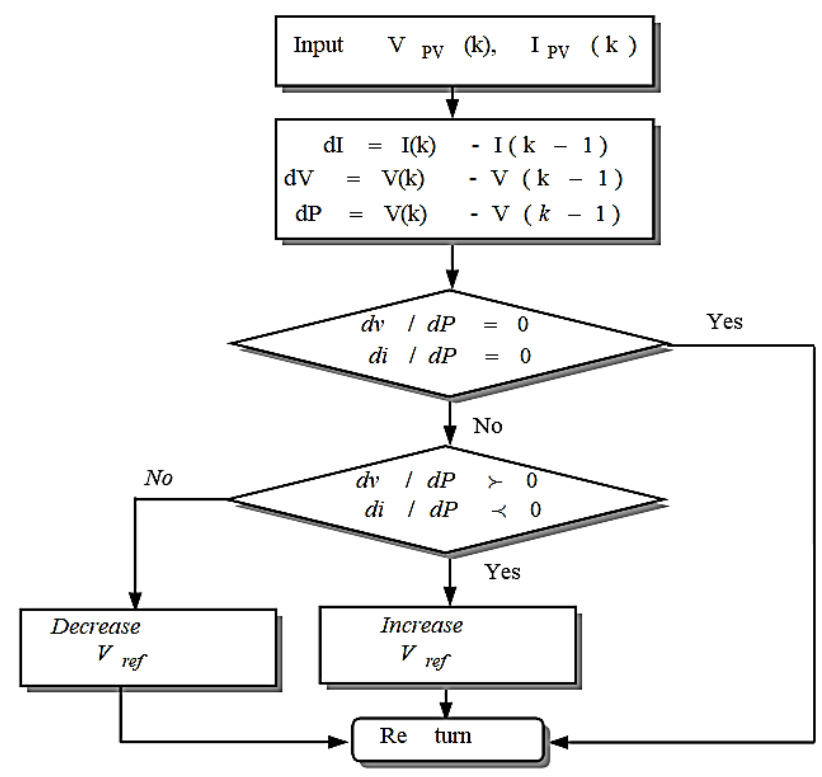

Figure 1. Incremental conductance algorithms [9]

\section{BOOST DC-DC CONVERTER for WIRELESS SENSORS}

The sensor is connected to the DC/DC switching converter to provide a regulated DC output voltage. The operation of the up-converter comprising two switches and an inductance shown in Figure $2[18,19]$. During the time, the power switch $S W_{1}$ is in $O N$ state, inductor current flows through the inductor $\mathrm{L}$ and the power switch $S W_{1}$ resulting in the current ramping up waveform [18]. During this energy the first is stored in the inductor and the voltage across the inductor is just the input voltage $V_{\text {in }}$ which provides half of the inductor Volt-Second balance. Hence modelling and analysis of the boost converter is an important step for designing this converter to satisfy the real requirements for the sensor [18, 20-22].

$$
\mathrm{D}=\frac{\mathrm{V}_{\text {in }}}{\mathrm{V}_{\text {out }}}=\frac{1}{1-\mathrm{d}}
$$

Applying inductor volt-second balance

$$
\mathrm{V}_{\text {in }} \mathrm{DT}+\left(\mathrm{V}_{\text {in }}+\mathrm{V}_{\text {out }}\right)(1-\mathrm{D}) \mathrm{T}=0
$$

The current of the inductor is always greater than zero during the whole switching period when the current of the inductor circulates continuously. In continuous conduction mode (CCM) and while the boost converter operates in (CCM) the output voltage can be regulated by controlling the duty cycle D the conversion ratio of the input and output voltage is given by (10). When the switch $\mathrm{S}$ is on the equivalent circuit $[18,23,24]$.

$$
\left\{\begin{array}{l}
\mathrm{L} \frac{\mathrm{di}_{\mathrm{L}}}{\mathrm{dt}}=\mathrm{V}_{\mathrm{g}}-\mathrm{V}_{0} \\
\mathrm{C} \frac{\mathrm{dV} \mathrm{V}_{0}}{\mathrm{dt}}=\mathrm{i}_{\mathrm{L}}-\frac{\mathrm{V}_{0}}{\mathrm{~L}}
\end{array}\right.
$$

If considering that the current passing through the inductance and the voltage across the capacitor as state variables then. State space equations can be written as follows

$$
\left\{\begin{array}{c}
{\left[\begin{array}{c}
\mathrm{i}_{\mathrm{L}} \\
\mathrm{v}_{\mathrm{C}}
\end{array}\right]=\left[\begin{array}{cc}
0 & \frac{1-\mathrm{d}}{\mathrm{L}} \\
-\frac{1-\mathrm{d}}{\mathrm{C}} & -\frac{1}{\mathrm{RC}}
\end{array}\right]\left[\begin{array}{c}
\mathrm{i}_{\mathrm{L}} \\
\mathrm{v}_{\mathrm{C}}
\end{array}\right]+\left[\begin{array}{l}
\frac{\mathrm{d}}{\mathrm{L}} \\
0
\end{array}\right] \mathrm{V}_{\text {input }}} \\
\mathrm{V}_{\text {ouput }}=\left[\begin{array}{ll}
0 & 1
\end{array}\right]\left[\begin{array}{l}
\mathrm{i}_{\mathrm{L}} \\
\mathrm{v}_{\mathrm{C}}
\end{array}\right]
\end{array}\right.
$$


where: $A_{I}=\left[\begin{array}{cc}0 & 0 \\ 0 & -\frac{1}{R C}\end{array}\right], B_{1}=\left[\begin{array}{c}\frac{1}{L} \\ 0\end{array}\right], C_{1}=\left[\begin{array}{ll}0 & 1\end{array}\right]$ and $\mathrm{u}=0$

Even when the switch is off, the circuit supplies the load directly from the source [18, 25].

$\left\{\begin{array}{l}\mathrm{L} \frac{\mathrm{di}_{\mathrm{L}}}{\mathrm{dt}}=\mathrm{V}_{\mathrm{g}}-(1-\mathrm{d}) \mathrm{V}_{0} \\ \mathrm{C} \frac{\mathrm{dV}_{0}}{\mathrm{dt}}=(1-\mathrm{d}) \mathrm{i}_{\mathrm{L}}-\frac{\mathrm{V}_{0}}{\mathrm{~L}}\end{array}\right.$

For duration ' $\left(1-D T_{s}\right)$ the average of the state equations on a commutation cycle gives the following equations the equations of state are given below.

$$
\left[\begin{array}{c}
\mathrm{i}_{\mathrm{L}} \\
\mathrm{v}_{\mathrm{C}}
\end{array}\right]=\left[\begin{array}{cc}
0 & \frac{1-\mathrm{d}}{\mathrm{L}} \\
-\frac{1-\mathrm{d}}{\mathrm{C}} & -\frac{1}{\mathrm{RC}}
\end{array}\right]\left[\begin{array}{c}
\mathrm{i}_{\mathrm{L}} \\
\mathrm{v}_{\mathrm{C}}
\end{array}\right]+\left[\begin{array}{c}
\mathrm{d} \\
\mathrm{L} \\
0
\end{array}\right] \mathrm{V}_{\text {input }}
$$

where :

$$
\mathrm{A}_{2}=\left[\begin{array}{cc}
0 & \frac{1}{\mathrm{~L}} \\
0 & -\frac{1}{\mathrm{RC}}
\end{array}\right], \mathrm{B} 2=\left[\begin{array}{c}
1 / \mathrm{L} \\
0
\end{array}\right], \mathrm{C}_{\mathrm{II}}=\left[\begin{array}{ll}
0 & 1
\end{array}\right]
$$

and

The averaged large signal module

$$
\begin{aligned}
& \mathrm{A}=\left[\mathrm{d} \cdot \mathrm{A}_{1}+(1-\mathrm{d}) \mathrm{A}_{2}\right] \\
& \mathrm{B}=\left[\mathrm{d} \cdot \mathrm{B}_{1}+(1-\mathrm{d}) \mathrm{B}_{2}\right] \\
& {\left[\begin{array}{l}
i_{L} \\
v_{c}
\end{array}\right]=\left[\begin{array}{cc}
0 & \frac{1-d}{L} \\
-\frac{1-d}{C} & -\frac{1}{R C}
\end{array}\right]\left[\begin{array}{l}
i_{L} \\
v_{C}
\end{array}\right]+\left[\begin{array}{l}
d \\
L \\
0
\end{array}\right] V_{\text {input }}} \\
& V_{\text {output }}=\left[\begin{array}{ll}
0 & 1
\end{array}\right]\left[\begin{array}{l}
i_{L} \\
v_{C}
\end{array}\right]
\end{aligned}
$$

From the average model, the equilibrium model is obtained by taking the derivative term zero $[18,25]$.

$$
\left[\begin{array}{l}
0 \\
0
\end{array}\right]=\left[\begin{array}{cc}
0 & 0 \\
0 & -\frac{1}{\mathrm{RC}}
\end{array}\right]\left[\begin{array}{l}
\mathrm{i}_{\mathrm{L}} \\
\mathrm{v}_{\mathrm{C}}
\end{array}\right]+\left[\begin{array}{l}
\frac{\mathrm{d}}{\mathrm{L}} \\
0
\end{array}\right] \mathrm{V}_{\text {input }}
$$

The state is given by $C_{I}=\left\lfloor\begin{array}{ll}0 & 1\end{array}\right\rfloor$ and Output matrix $Y=[C] X$

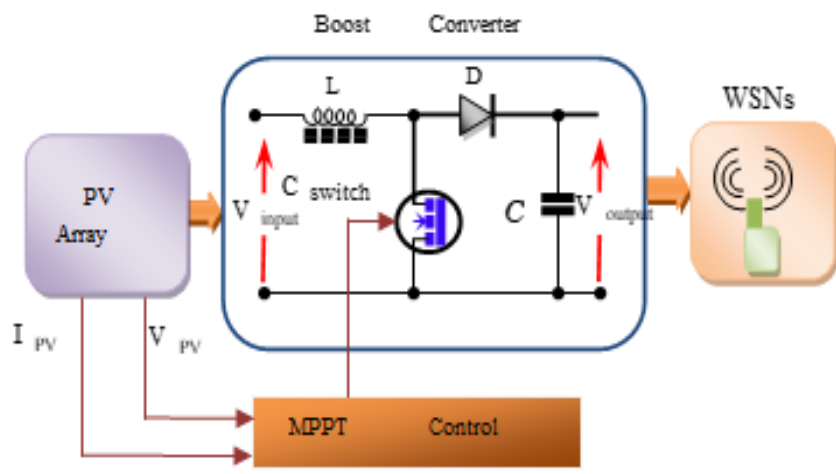

Figure 2. The boost DC-DC converter for node of wireless sensor networks 


\section{SIMULATION RESULTS}

Following the model proposed in Figure 2, the simulation was carried out to study the wireless sensor network comportment. In this model, a type of sensor is used to respond well to our study. Sensors come from Telos Mote of Berkeley, and which is characterized by its tension is $4.5 \mathrm{~V}$ and which can adapt to the maximum voltage of $5 \mathrm{~V}$ and can work at $1.8 \mathrm{~V}$ that is a considerably low voltage. Reference voltages of Telos are only $2.5 \mathrm{~V}$ and $1.5 \mathrm{~V}$ connecting to solar panel PV. For the solar panel, Sun-Ceram $3.5 \times 7.8 \mathrm{cmis}$ chosen, this solar panel has a lower cost and easily available, in this region a typical solar cell produces around 0.5 to 0.8 volts and output is about $20 \%$ in this area of study, which corresponds to a power of 20 $\mathrm{mW} / \mathrm{cm} 2$ under direct sunlight and moreover, it is suitable for our Telos sensor.

This PV solar panel connected to the sensor node via the DC-DC Boosts convertercontrolled by maximum power point tracking (MPPT) technique, using the incremental conductance (IC) algorithm to extract maximum power under different scenarios (temperature and radiation) whose objective is to ensure a constant output voltage of $5 \mathrm{~V}$, The following results were performed under the MATLAB/SIMULINK environment Figure 3. In the beginning, there is an illustration about the efficiency of the PV panel, in this study area, and then behaviour of the sensor node connects to the same solar panel in this hot region subject to different scenarios Figure 4.

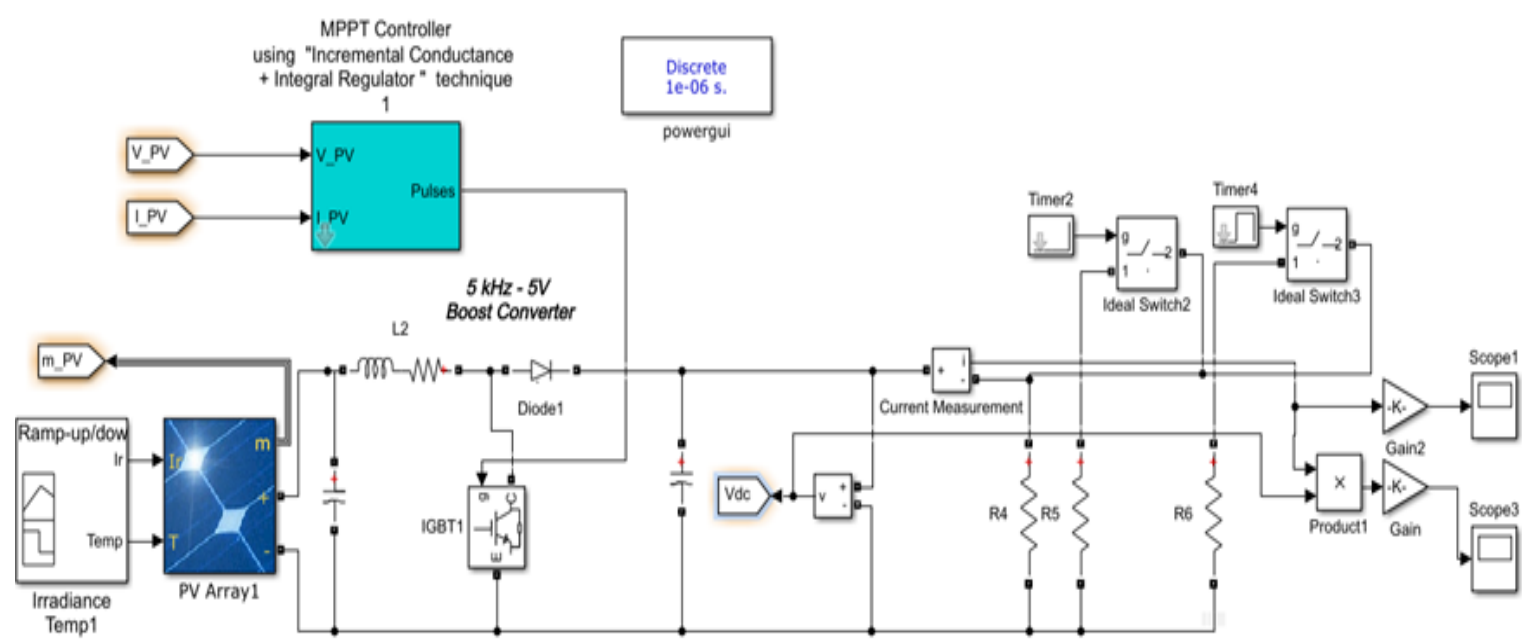

Figure 3. Modele of one node of wireless sensor networks in MATLAB/Simulink

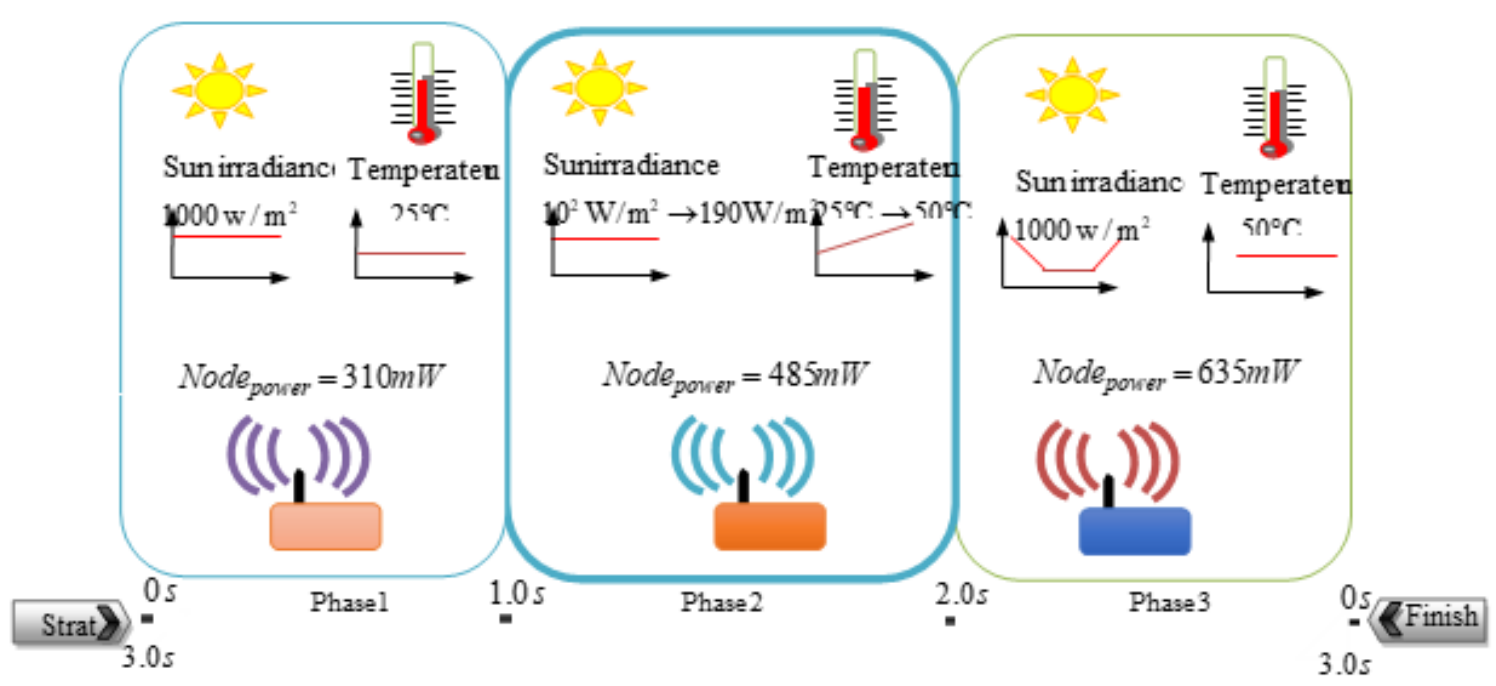

Figure 4. Node of wireless sensor network scenarios 


\subsection{PV panel results}

The current-voltage I-V and power- voltageP-V curve respectively in different insulation conditions the temperature is fixed to $25^{\circ} \mathrm{C}$, star point shows peak power of each curve, as insulation increases peak power shifted upwards. It is clearly shown in P-V graph, when irradiations increase, the power increase dramatically Figure 5. The I-V and P-V curve in different temperature conditions, star point shows peak power of each curve, as temperature increases peak power shifted downwards. It is very interesting to discuss the P-V curve, when the temperature increase the power of module increase too Figure 6.
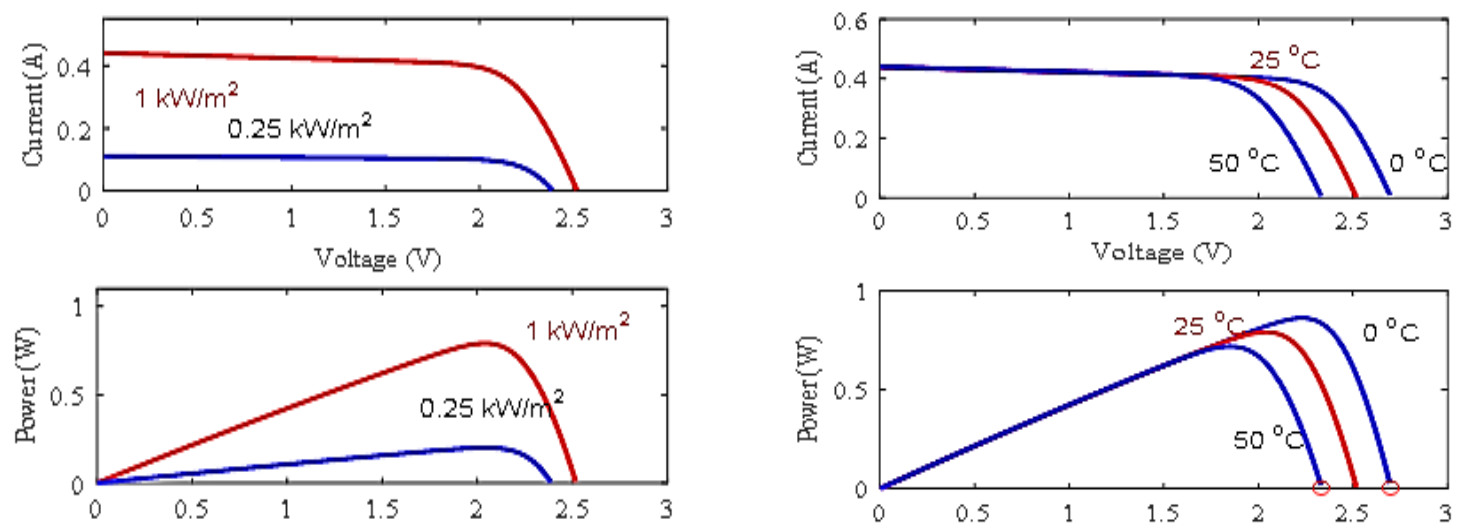

Figure 5. I-V and P-V characteristic of a solar array for a fixed temperature but varying irradiance for PV module

Figure 6. I-V and PV characteristic of a solar array for a fixed irradiance e but varying temperature for PV module

\subsection{Compartment of WSN in Hottest regions}

To study behaviour and test performance of WSN, the proposed system is subject to several topologies. Figure 4 shows the detail. The topologies are divided into three phases. In the first phase, the temperature is $25^{\circ} \mathrm{C}$ and the irradiation is set at $1000 \mathrm{~W} / \mathrm{m} 2$. The power node is $310 \mathrm{~mW}$. In the second case, the irradiation is maintained but the temperature increases and reaches the supply node can reach $50^{\circ} \mathrm{C}$ up to $485 \mathrm{~mW}$. The third one, temperature is maintained at $50^{\circ} \mathrm{C}$ and the irradiation increases the increase of the supply node to $635 \mathrm{~mW}$. Temperature variation and radiation are illustrated in Figure 4.

These three phases can be adapted to the operations of the node according to its energy consumption, so that the first phase is in phase of small energy consumption; it is the acquisition and the treatment of the data, the second phase the Average consumption is the listening phase of the channel, and finally the third phase can be linked to the transmission and reception of data, where the node consumes more and more energy. Figure 7 illustrates the variation of the voltage in different scenarios. This curve proves the robustness of the MPPT controller using the IC algorithm, despite the variation in temperature and radiation. Figure 8 shows the output power of the boost converter in different scenarios.

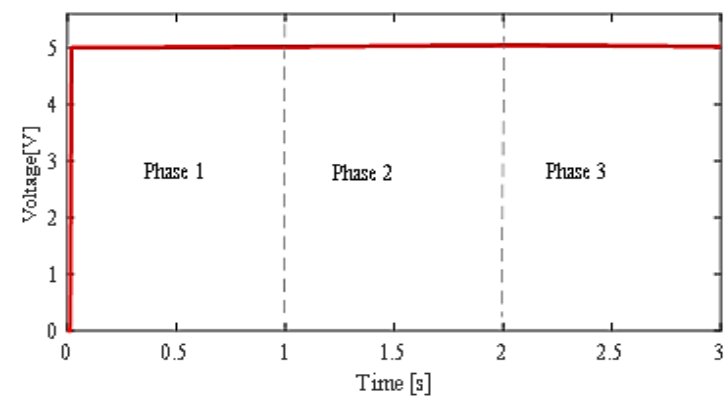

Figure 7.Variation of node voltage in different phases

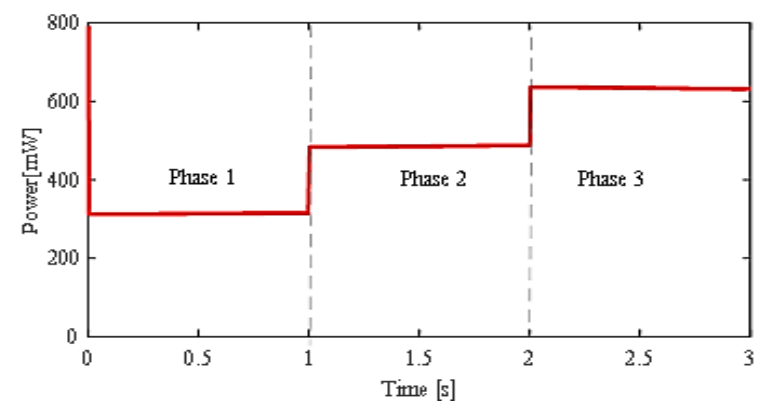

Figure 8. Variation of node power in different phases 
In Figure 9 shows Vpv from the panel in the different phases. The variation of the voltage in the sensor node remains almost fixed at $5 \mathrm{~V}$ since the variation of the voltage and the current is the same through the three phases following the variation of the output resistance, disturbances have no effect on the output voltage efficiency of the DC-DC boost converter.Temperature variation and irradiation do not affect the WSN behaviour, so the conclusion is the efficiency of the maximum power point tracing technique using the conductance increment algorithm.

Figure 10 illustrates the change in the duty cyclewhich exactly matches the service of our sensor nodethat is to say the acquisition of signals, treatment and communication. The nodal variation of current, which is almost the same as the power nodal variation in Figure 8, is observed in Figure 11 and consequently gives it the variation of $\mathrm{V}$ mean voltage in the different phases Figure 12, according the boost converter is examined by varying the output node resistor, the variation of the voltage in the node still remains around $5 \mathrm{~V}$. The disturbances do not distract the efficiency of the boost DC-DC converter output voltage is illustrated in Figure 13. The variation of temperature and temperature is not affect the behaviour of the WSN, the conclusion is the efficiency of the maximum power point tracing technique using the incrimination of conductance algorithm.

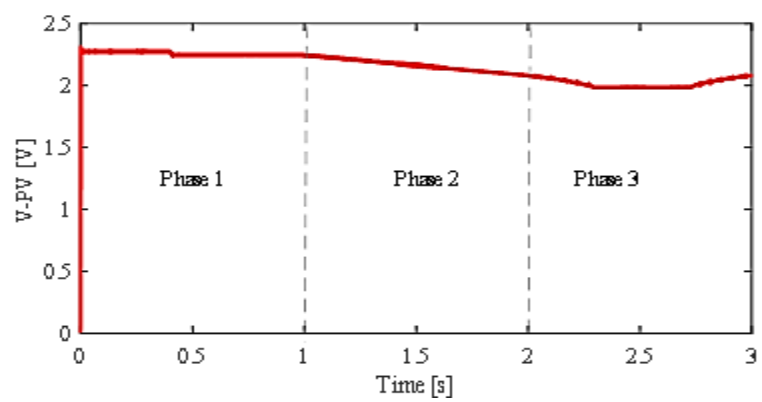

Figure 9. Variation of $\mathrm{Vpv}$ from de panel in different phases

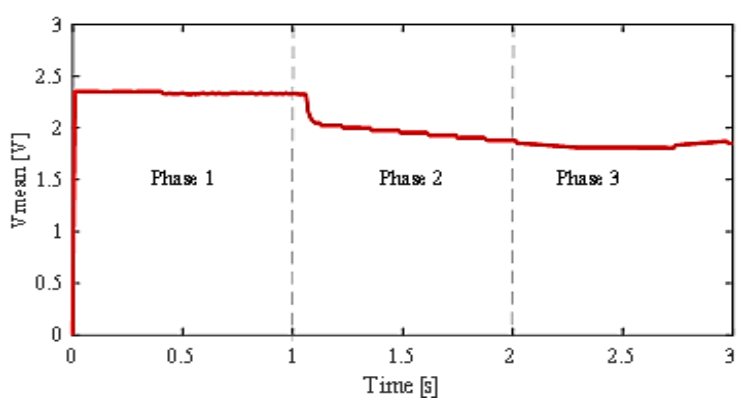

Figure 11.Variation of $\mathrm{V}$ means voltage in different phases

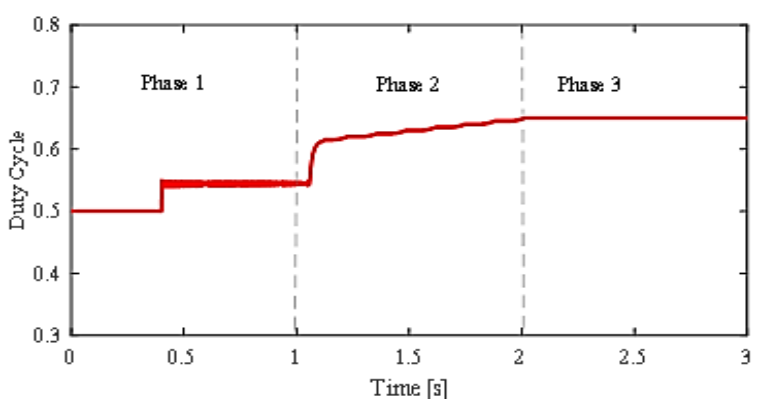

Figure 10. Duty cycle of bidirectional DC-DC converter in different cases

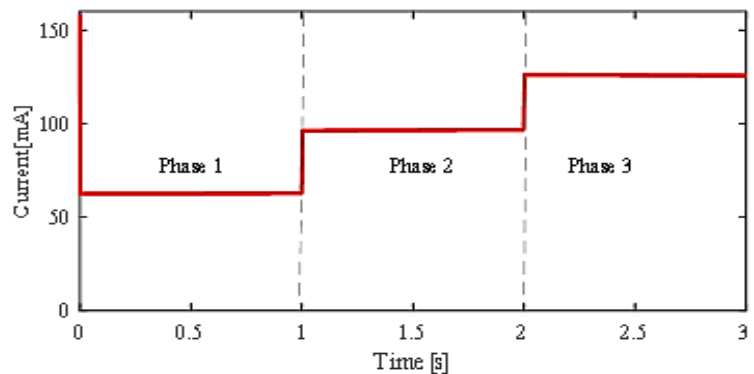

Figure 12. Variation of current in different phases

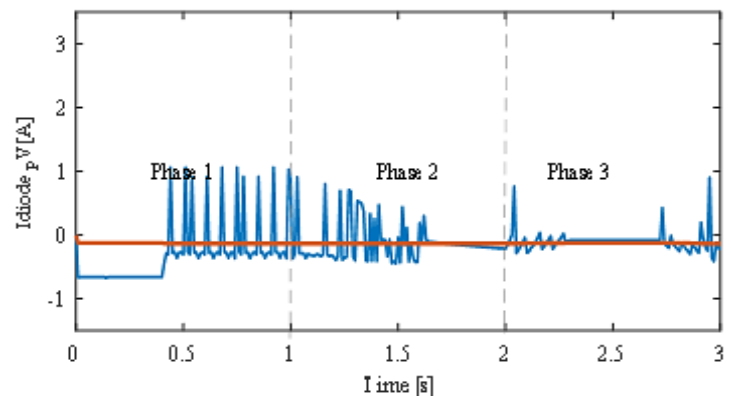

Figure 13. Variation of I diode of the PV panel in different phases 


\section{CONCLUSION}

This article presents a model for sensorsin a hot region whose long-term goal of wireless sensor network operation the MPPT method controlled by the IC algorithm seems very suitable for the supply of wireless sensor nodes in the Saharan region, andeven the power variations does not interfere with the performance of the boost converter. In addition, the user types of wireless sensor networks in the employ is more than $50 \%$ of the time remains in active state (multi-media sensor, mobile sensor) and even communication sectors that are essentially trying to maximize energy and minimizing costs should take into account the results on the steps of this study.

\section{ACKNOWLEDGEMENTS}

The authors would like to thanks the laboratory of energy in arid region (ENERGARID) Bechar University and laboratory of smart grids \& renewable energy (SGRE) faculty of technology, department of electrical Engineering, tahri mohamed university Bechar Algeria.

\section{REFERENCES}

[1] A. Randrianarisaina, O. Pasquier, P. Chargé, "Energy Consumption Modelingof Smart Nodes with a Function Approach," Proceedings of the 2014 Conference on Design and Architectures for Signal and Image Processing, Madrid, pp. 1-6, 2014.

[2] Imededine Djadour, Aidel Salih, Hicham Medkour, "Design and implementation of low power consumption wireless sensor node," TELKOMNIKA (Telecommunication, Computing, Electronics and Control), vol. 17, no. 6, pp. 2729 2734 ISSN: 1693-6930, December 2019.

[3] Boubakeur H., Khelifa B., Brahim G., "Comparative studies between Lithium-Ion, Nickel Caduim and Nickel Metal hydride Batteries for wireless sensor Networks," The 6th International Renewable Energy Conference CIER 2018 Hammamet, Tunisie, December 2018.

[4] J. C. Rosas-Caro, J. M. Ramirez, F. Z. Peng, A. Valderrabano, "A DC-DC multilevel boost converter," in IET Power Electronics, vol. 3, no. 1, pp. 129-137, January 2010.

[5] S. E. Abdellaoui, Y. Fakhri, S. Saoudiet D. Aboutajdine, "Energy Efficiency of MIMO Cooperative Networks with Energy Harvesting Sensor Nodes," International Journal of Ad hoc, Sensor and Ubiquitous Computing (IJASUC), vol. 4, no. 2, pp. 1-16, April 2013.

[6] K. Z. Panatik, K. Kamardin, S. A. Shariff1, S. Yuhaniz, N. A. Ahmad, O. M. Yusop, S. Ismail, "Energy Harvesting in Wireless Sensor Networks: A Survey," 2016 IEEE 3rd International Symposium on Telecommunication Technologies (ISTT), Kuala Lumpur, pp. 53-58, 2016.

[7] Evizal Abdul Kadir, Hitoshi Irie, Sri Listia Rosa, Mahmod Othman, "Modelling of wireless sensor networks for detection land and forest fire hotspot," TELKOMNIKA Telecommunication, Computing, Electronics and Control, vol. 17, no. 6, pp. 2772 2781 ISSN: 1693-6930, December 2019

[8] G. Sureshkumaar1, Nithiyananthan Kannan2, Sunil Thomas3, "MATLAB/SIMULINK based simulations of KY converter for PV panels powered led lighting system," International Journal of Power Electronics and Drive system (IJPEDS), vol. 10, no. 4, pp. 1885 1893, ISSN: 2088-8694, December 2019.

[9] RatnalkaPutri, Sapto Wibowo, Muhamad Rifa, "Maximum power point tracking for photovoltaic using incremental conductance method," Energy Procedia, vol. 68, pp. 22-30, April 2015.

[10] Mustafa A. Fadel Al-Qaisi, Mohanad A. Shehab, Ammar Al-Gizi, Mohammed Al-Saadi, "High performance DC/DC buck converter using sliding mode controller," International Journal of Power Electronics and Drive System (IJPEDS), vol. 10, no. 4, pp. 1806 1814 1806, ISSN: 2088-8694, December 2019.

[11] Ahmad Al Nabulsi, RachedDhaouadi, Habib-Ur Rehman, "Single input fuzzy controller (SFLC) based maximum power point tracking," 2011 Fourth International Conference on Modeling, Simulation and Applied Optimization, Kuala Lumpur, pp. 1-5, 2011.

[12] Anane, R., K. Raoof, et al., "On the Evaluation of GMSK Scheme with ECC Techniques in Wireless Sensor Network," International Journal of Wireless \& Mobile Networks (IJWMN), vol. 7, no. 2, pp. 17-28, April 2015.

[13] B. Gasbaoui, A. Nasri, O. Abdelkhalek, J. Ghouilib, A. Ghezouani, "Behavior PEM fuel cell for 4WD electric vehicle under different scenario consideration," International Journal of Hydrogen Energy, vol. 42, no. 1, pp. 535-543, 5 January 2017.

[14] J. Moreno, J. Dixon, and M. Ortuzar, "Energy management system for an electric vehicle, using ultra capacitors and neural networks," in IEEE Transactions on Industrial Electronics, vol. 53, no. 2, pp. 614-623, April 2006.

[15] S. Vijaya Madhavi, G. Tulasi Ram Das, "Variable structure control for an isolated boost converter used in fuel cell applications," International Journal of Electrical and Computer Engineering (IJECE), vol. 9, no. 6, pp. 4493-4506, ISSN. 2088-8708, December 2019.

[16] Y .P. Yang, C. P. Lo: "Current Distribution Control of Dual Directly Driven Wheel Motors for Electric Vehicles," Control Engineering Practice, vol. 16, no. 11, pp. 1285-1292, November 2008.

[17] Gao M., He S., "Self-adapting Fuzzy-PID Control of Variable Universe in the Non-linear System," 2008 International Conference on Intelligent Computation Technology and Automation (ICICTA), Hunan, pp. 473-478, 2008 . 
[18] K. LathaShenoy, C. GurudasNayak, and Rajashekar P. Mandi, "State space analysis of boost DC/DC converter with voltage mode control," in AIP Conference Proceedings, vol. 1859, no. 1, 020062, July 2017.

[19] Q. Zhang, Y.Y in, "Analysis and Evaluation of Bidirectional DC/DC Converter," Journal of Power Technology, vol. 1, no. 4, pp. 331-338, 2003.

[20] B. Allaoua, B. Mebarki, and A. Laoufi, "A Robust Fuzzy Sliding Mode Controller Synthesis Applied on Boost DC-DC Converter Power Supply for Electric Vehicle Propulsion System," in International Journal of Vehicular Technology, vol. 2013, no. 1, pp. 1-9, May 2013.

[21] Y. V. Siva Reddy, M. Vijayakumar and T. Brahmananda Reddy, "Direct Torque Control of Induction Motor Using Sophisticated Lookup Tables Based on Neural Networks," AIML Journal, vol. 7, no. 1, June 2007.

[22] H. J. Chill, L. W. Lin, “A Bidirectional DC-DC Converter for Fuel Cell Electric Vehicle Driving System," in IEEE Transactions on Power Electronics, vol. 21, no. 4, pp. 950-958, July 2006.

[23] Nadjat Benadla, KheireddineGhaffour, "Optimizing the performance of photovoltaic cells IBC (interdigitated back contact) by numerical simulation," International Journal of Electrical and Computer Engineering (IJECE), vol. 9 no. 6, pp. 4566-4572, December 2019.

[24] SASIKUMAR .S, HARINANDAN. L., "Automatic Power Management And Monitoring System For Electric Vehicles," International Journal of Technology Enhancements And Emerging Engineering Research, vol. 2, no. 4 ISSN: 2347-4289, pp. 134-137, 2014.

[25] B. Allaoua, and B.Mebarki, "Hybrid Energy Source Management Composed of a Fuel Cell and Super-Capacitor for an Electric Vehicle," Advances in Automobile Engineering, vol. 5, no. 2, ISSN: 2167-7670, 2016. 